\title{
OZONÓLISE: A BUSCA POR UM MECANISMO
}

\author{
Alfredo R. M. Oliveira* e Celso L.Wosch \\ Departamento de Química, Universidade Federal do Paraná, CP 19081, 81531-990 Curitiba - PR, Brasil
}

Recebido em 27/10/11; aceito em 29/1/12; publicado na web em 30/4/12

\begin{abstract}
OZONOLYSIS: THE SEARCH FOR A MECHANISM. The ozonolysis reaction is widely used in the academy and in industry. The first reports about the existence of the ozone molecule were made over 200 years ago. Several ideas and assumptions were made to understand the chemical properties of the ozone molecule and the ozonolysis mechanism. The intent of this paper is not to be an extensive review about ozone chemistry or ozonolysis reactions, but to highlight how the rational process was developed and how conclusions were drawn at a time with limited instrumentation.
\end{abstract}

Keywords: ozone; ozonolysis mechanism; historical approach.

\section{INTRODUÇÃO}

A reação de ozonólise tem sido muito utilizada tanto na academia como na indústria. Isto se deve à facilidade com que o ozônio oxida ligações duplas, formando uma variedade de compostos carbonílicos que podem ser transformados ou utilizados posteriormente. Como exemplo, a identificação da posição de uma ligação dupla em um hidrocarboneto pode ser rapidamente determinada utilizando-SE a reação de ozonólise seguida pela análise dos fragmentos formados. Há 171 anos, Schönbein iniciou os trabalhos de investigação das propriedades de um novo gás, o ozônio, e apenas em 1975 foi possível propor o mecanismo aceito atualmente. Durante este período, vários pesquisadores se envolveram com o tema, alguns com propostas que hoje seriam consideradas absurdas, mas que fizeram parte do desenvolvimento das ideias que finalmente culminaram com a proposta feita por Criegee, em 1975.

Este artigo não pretende ser uma revisão extensiva do assunto, mas sim chamar a atenção sobre as principais ideias propostas ao longo do tempo para se determinar o mecanismo da reação de ozonólise.

\section{UM POUCO DE HISTÓRIA}

Em 1783, o filósofo e cientista holandês Martin van Marum descreveu pela primeira vez que o ar perto de sua máquina eletrostática (hoje no Museu de Haarlem, Holanda, baseada em garrafas de Leiden) adquiria um odor diferente quando emitia descargas elétricas. Em 1801, Cruickshank observou que o oxigênio produzido pela eletrólise de soluções de ácidos diluídos em certas condições possuía um odor característico e diferente. Estes dois investigadores apenas relataram as observações feitas, mas não procuraram descobrir qual substância era responsável por aquele odor.

Em 1840, Schönbein reconheceu que o odor gerado, tanto por uma descarga elétrica como pela eletrólise de soluções ácidas diluídas, era

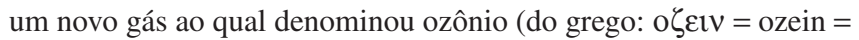
cheirar). Durante estes estudos, Schönbein sugeriu a hipótese de que o ozônio ou oxigênio ativo era produzido pela ruptura da ligação neutra oxigênio-oxigênio formando o ozônio $\left(\mathrm{O}^{-}\right)$e seu isômero elétrico, o antiozônio $\left(\mathrm{O}^{+}\right)$(Equação 1). ${ }^{1}$

$$
\mathrm{O}_{2} \rightarrow \mathrm{O}^{+}+\mathrm{O}^{-}
$$

\footnotetext{
*e-mail: armo@ufpr.br
}

Em carta para Faraday, Schönbein revelou: I am far from believing that the above is correct but it is necessary to have a hypothesis on which to base further experiment. ${ }^{2}$ (tradução: Realmente não acredito que a ideia acima esteja correta, mas é necessário ter uma hipótese sobre a qual basear experimentos futuros.) A partir desta hipótese, seria previsível a formação de "ozonídeos" e "antiozonídeos" e isto incentivou vários pesquisadores a procurar, infrutiferamente, por estas espécies. Algumas propostas feitas sobre a real composição do ozônio não possuíam nenhuma evidência experimental: Williamson sugeriu que poderia ser peróxido de hidrogênio gasoso e Baumert considerou que o ozônio fosse uma forma oxidada do peróxido de hidrogênio, $\mathrm{H}_{2} \mathrm{O}_{3}$. Bequerel e Freny foram os primeiros a demonstrar que o oxigênio poderia ser totalmente convertido em ozônio. Isto foi feito usando um experimento relativamente simples: em um tubo de descargas elétricas contendo oxigênio foi gerado ozônio na presença de uma solução de KI e, assim, o ozônio era consumido na medida em que era formado. Após algum tempo, todo o oxigênio havia sido consumido, comprovando que o ozônio era uma forma alotrópica do oxigênio (Equação 2). ${ }^{3}$

$$
\mathrm{O}_{3}+2 \mathrm{KI}+\mathrm{H}_{2} \mathrm{O} \rightarrow \mathrm{I}_{2}+2 \mathrm{KOH}+\mathrm{O}_{2}
$$

Em 1876, Soret fez os seguintes experimentos: em um tubo com volume $V$ conhecido e munido de um manômetro de ácido sulfúrico (Esquema 1), foi aplicada uma descarga elétrica até uma contração no volume do gás (v). Ao aquecer o tubo a $273{ }^{\circ} \mathrm{C}$ o volume $V$ foi restaurado, o que indicava que a decomposição do ozônio formado regenerava o oxigênio que havia sido consumido. Ao gerar uma quantidade de ozônio ( $\mathrm{V}-v$ ) e destruir o ozônio formado com uma solução de KI (Equação 2), Soret observou que não havia mudança no volume final registrado $(V-v)$, apesar de todo o ozônio ter sido destruído. Da mesma maneira, ao reagir um volume de ozônio com prata metálica não havia variação no volume $(V-v)$, segundo a Equação 3:

$$
\mathrm{O}_{3}+2 \mathrm{Ag}^{0} \rightarrow \mathrm{Ag}_{2} \mathrm{O}+\mathrm{O}_{2}
$$

Ao gerar ozônio na presença de óleo de terebentina (cuja composição principal é uma mistura de $\alpha$ e $\beta$-pineno) ou de canela (cuja composição contém cinamaldeído), foi observada uma contração do volume, cujo valor final atinge $(\mathrm{V}-3 v)$. Um volume $v$ é resultado da formação do ozônio e dois volumes $v$ são consumidos na reação do ozônio com o óleo de terebentina (ou cinamaldeído). Assim, 3/2 volumes de oxigênio é igual a um volume de ozônio, Equação 4: 


$$
3 / 2 \mathrm{~V} \mathrm{O}_{2}=1 \mathrm{~V} \mathrm{O}_{3} \text { ou } 3 \mathrm{O}_{2}=2 \mathrm{O}_{3}
$$

Soret atribuiu a estrutura 1 (Esquema 1) ao alótropo triatômico do oxigênio e confirmou a existência do ozônio ao medir sua densidade, que é 1,5 vezes a densidade do oxigênio.

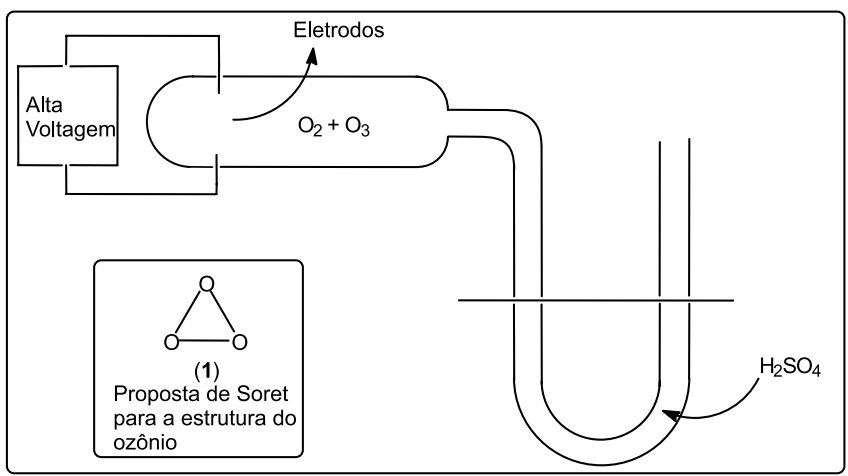

Esquema 1. Aparelho de Soret

O ozônio possui um cheiro forte e característico e pode ser detectado pelo olfato humano em menos de 0,01 partes por milhão. Não existe um acordo quanto à descrição do cheiro que já foi registrado como parecido com enxofre, cloro, fósforo ou mesmo lagosta ou peixe. Soluções diluídas de ozônio em oxigênio são praticamente incolores, mas quando vistas através de um tubo com cerca de $2 \mathrm{~m}$ de comprimento, no sentido longitudinal, adquirem uma tonalidade azul céu. ${ }^{4}$

\section{A PROCURA POR UM MECANISMO}

Para o desenvolvimento de uma proposta que explicasse o mecanismo da reação de ozonólise foram importantes os relatos sobre as decomposições e explosões dos ozonídeos formados. O ozônio, quando borbulhado em um frasco contendo eteno na superfície, produz bolhas explosivas e um cheiro forte de ácido fórmico e de formaldeído. Por outro lado, a tentativa de fazer a ozonólise do benzeno e isolar o ozonídeo levou à decomposição do mesmo, deixando um forte cheiro de ácido acético no ar. ${ }^{5}$ Deve-se lembrar que estes relatos foram feitos em meados do século XIX, quando as observações organolépticas eram fundamentais para as investigações.

Várias possibilidades a respeito da estrutura molecular do ozônio foram sugeridas e até 1905 apenas duas pareciam ser as mais prováveis: a estrutura 1, sugerida por Soret, e um arranjo linear $(\mathrm{O}=\mathrm{O}=\mathrm{O})$ 3, proposto por Harries, pela similaridade com $\mathrm{O}=\mathrm{S}=\mathrm{O} \cdot{ }^{6}$ Utilizando a estrutura 3, Harries propôs que a reação de adição a uma dupla ligação deveria formar o ozonídeo 4 (Esquema 2), porém não foi possível confirmar este fato usando os dados experimentais obtidos.

$\mathrm{Na}$ tentativa de comprovar a estrutura do ozonídeo 4, Harries, Pummerer e Fisher tentaram fazer a redução dos ozonídeos formados, utilizando como agentes redutores hidroquinona, hidrazobenzeno, amálgama de alumínio e zinco e hidrogenação catalítica a $0{ }^{\circ} \mathrm{C}$; não foi possível observar nem a regeneração do material de partida e nem a formação do glicol, que seria esperado pela redução do ozonídeo 4. Entre 1901 e 1916, Harries investigou esta reação publicando mais de 90 artigos sobre o ozônio, suas propriedades e reações com compostos orgânicos, estabelecendo sua utilidade ao desenvolver uma metodologia que permitia localizar a posição de uma ligação dupla em uma molécula orgânica. ${ }^{7}$

As estruturas propostas (1) e (3), por serem neutras, não poderiam explicar a extrema reatividade do ozônio e foram substituídas, em 1923, pela proposta de Lowry, ${ }^{8}$ onde a molécula de ozônio, ainda linear, possuía um dipolo elétrico $\left({ }^{-} \mathrm{O}-\mathrm{O}^{+}=\mathrm{O}\right)$. Em 1925, Staudinger $^{8}$

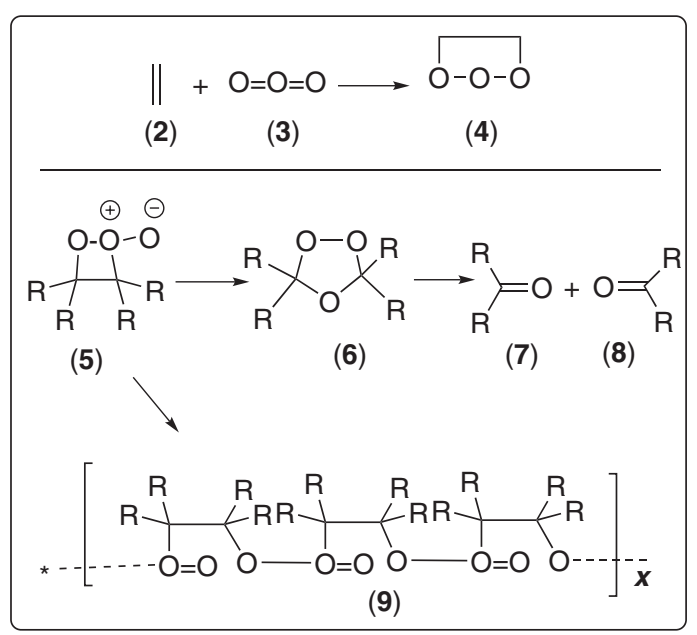

Esquema 2. Propostas de Harries e Staudinger

sugeriu que a estrutura 6, a qual denominou isozonídeo, explicaria melhor os resultados observados. ${ }^{8}$ Nesta proposta, a ligação carbono-carbono já estaria quebrada e, assim, a decomposição de $\mathbf{6}$ levaria à formação apenas dos produtos carbonílicos anteriormente observados e justificaria a inexistência de glicóis por reação de redução (Esquema 2).

Como possível precursor de $\mathbf{6}$ foi proposto o molozonídeo $\mathbf{5}$ que poderia ser estabilizado, após um rearranjo, formando $\mathbf{6}$, ou via polimerização formando 9 (Esquema 2).

Entre 1925 e 1953, os avanços experimentais foram consideráveis, mas faltava o conhecimento teórico sobre a molécula de ozônio e sem este conhecimento fundamental qualquer proposta de ataque inicial não poderia ser elaborada e confirmada. Até 1948 os espectroscopistas que tentaram elucidar a estrutura da molécula de ozônio concordavam: a melhor representação da molécula de ozônio era um triângulo isósceles. ${ }^{9}$ Até o início da década de $1970^{10}$ havia discordâncias fundamentais sobre o assunto. Por esta razão, Criegee dedicou sua atenção ao estudo dos produtos mais oxigenados provenientes da ozonólise, deixando de lado a etapa inicial da reação. Como resultado destas investigações, em 1953, propôs o seguinte mecanismo (Esquema 3) para a reação de ozonólise: ${ }^{11}$

Sem se aprofundar na estrutura de adição inicial 11, Criegee sugeriu a existência do zwitterion $\mathbf{1 3}$ e quatro caminhos possíveis para

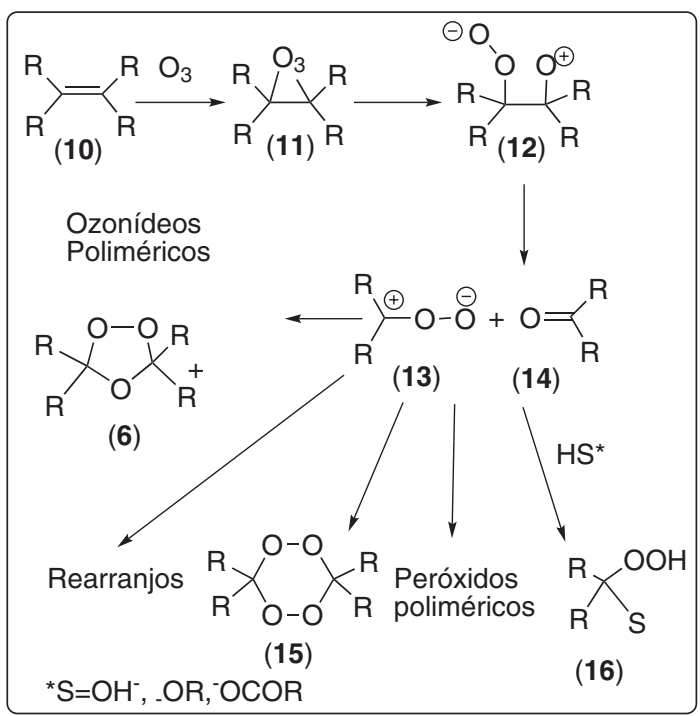

Esquema 3. Primeira proposta feita por Criegee, em 1953 
a sua decomposição. A reputação de que ozonídeos são explosivos se deveu, provavelmente, aos peróxidos poliméricos ou aos dímeros 15, que são instáveis por natureza e cujo isolamento nem sempre é possível. Apenas as espécies de cinco membros como a estrutura 6 devem ser chamadas de ozonídeos e vários são estáveis a ponto de poderem ser destilados e purificados. Como exemplo, os compostos 1-penteno, 1-exeno, 2-exeno, 2-octeno, 3,3-dimetil-1-buteno, estireno e estilbeno formam ozonídeos que não são explosivos. ${ }^{11}$ Quando a ozonólise é feita em um solvente inerte, alguns ozonídeos podem ser isolados e possuem pontos de fusão ou ebulição bem definidos, permitindo sua purificação. ${ }^{12}$

A estrutura dos ozonídeos foi comprovada pelo isolamento do ozonídeo 19 a partir da ozonólise do 1,2-dimetil-ciclopenteno 17 e confirmada pela síntese independente do mesmo ozonídeo (19). A reação de 1,3-heptanodiona 21 com peróxido de hidrogênio leva à formação do peróxido cíclico $\mathbf{2 0}$ que, ao ser desidratado com $\mathrm{P}_{2} \mathrm{O}_{5}$, forma o ozonídeo 19 (Esquema 4).

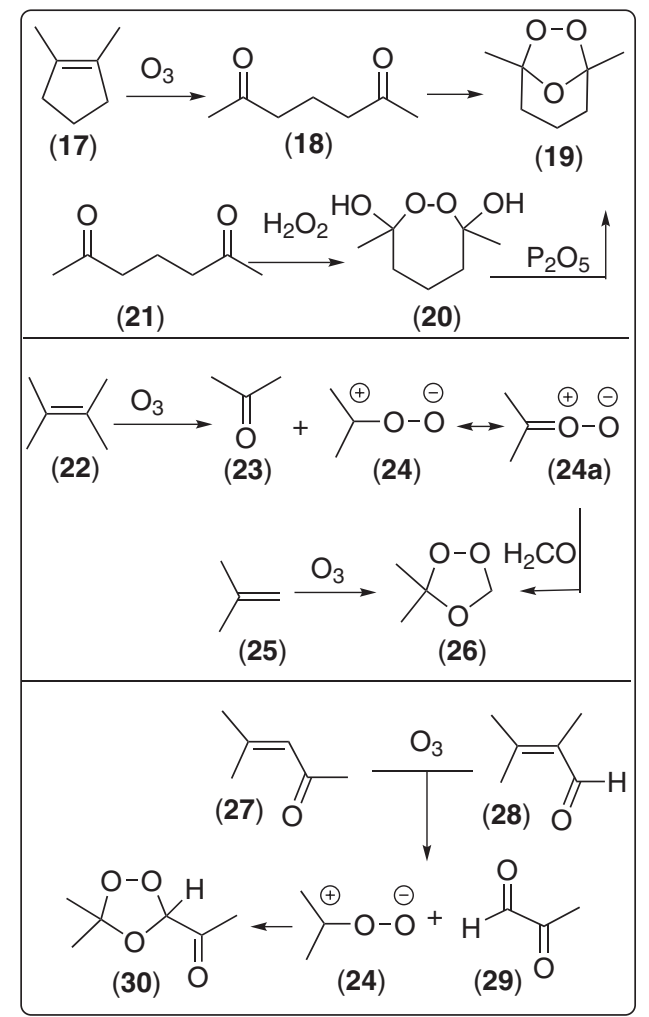

Esquema 4. Comprovação da estrutura do ozonídeo 19 e da existência do zwitterion 24

Uma vez comprovada a estrutura do ozonídeo 19 como intermediário da reação, a existência de espécies do tipo zwitterion 13 foi confirmada pelo seguinte experimento: a ozonólise do tetrametileteno 22 na presença de formaldeído resulta exclusivamente na formação do ozonídeo derivado do isobuteno $\mathbf{2 6}$, ao invés do dímero ou dos peróxidos poliméricos correspondentes. Isto demonstrou que, após a etapa inicial, havia uma etapa de dissociação, que poderia ser explicada pela existência do zwitterion 24.

Outro experimento que ajudou na comprovação do mecanismo proposto foi a ozonólise do óxido de mesitila 27 e do crotonaldeído 28, onde somente a formação do ozonídeo $\mathbf{3 0}$ foi identificada como produto da reação. A formação exclusiva do ozonídeo $\mathbf{3 0}$ como produto nas duas reações permitiu o entendimento da organização estereoeletrônica e a reatividade do zwitterion $\mathbf{2 4}$ durante o curso da reação de ozonólise.

\section{A VISÃO ATUAL DA REAÇÃO DE OZONÓLISE}

Em 1963, Huisguen propôs que a molécula de ozônio se comportasse como um dipolo 1,3 e possuísse os híbridos de ressonância ${ }^{13}$ que constam no Esquema 5.

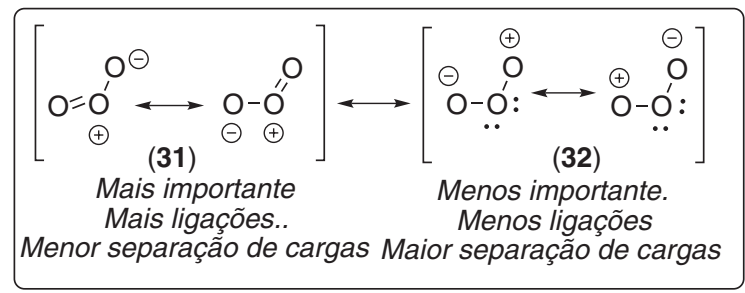

Esquema 5. Estruturas de ressonância da molécula de ozônio

Apenas em 1975, Criegee propôs que a etapa inicial ocorresse via cicloadição 1,3 -dipolar do ozônio $(4 s+2 s)$ à olefina, formando um molozonídeo instável 34, que é seguido por uma ciclorreversão, formando o zwitterion 36 (ou óxido de carbonila) e um composto carbonílico. Uma nova cicloadição forma o ozonídeo $37^{14}$ (Esquema 6).

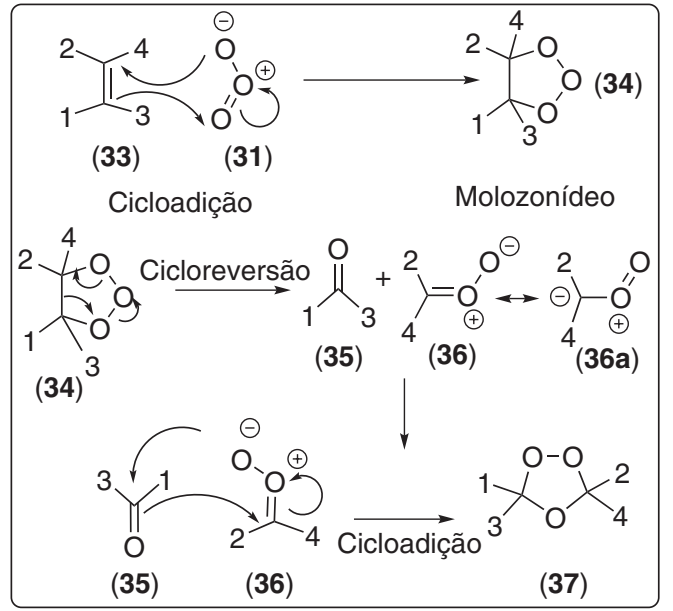

Esquema 6. Proposta do mecanismo de Criegee

Apesar do molozonídeo 34 se decompor rapidamente, existem evidências espectroscópicas obtidas por ${ }^{1} \mathrm{H}$ RMN a $-130{ }^{\circ} \mathrm{C}$ sobre sua existência. ${ }^{15}$ Em $2000,{ }^{16}$ o zwitterion 40, que é estável em solução a $-80^{\circ} \mathrm{C}$, foi sintetizado pela reação do difenil carbeno $\mathbf{3 9}$ com oxigênio elementar (Esquema 7).

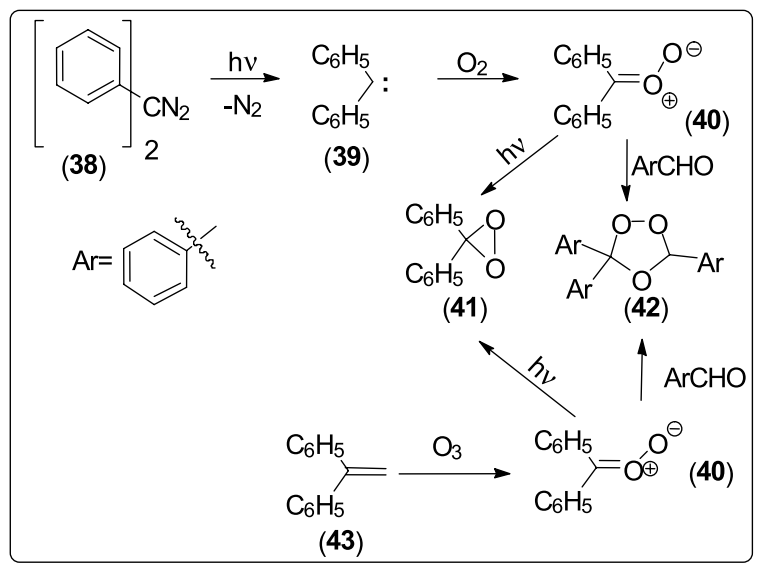

Esquema 7. Síntese do zwitterion (39) 
O composto 40 também foi obtido pela reação de ozonólise do 1,1-difenil-eteno $\mathbf{4 3}$. O zwitterion 40 reage da mesma maneira com aldeídos formando $\mathbf{4 2}$, independente da maneira como foi gerado. A irradiação do composto $\mathbf{4 0}$, obtido por qualquer dos dois métodos, forma o difenildioxirano 41 , que é estável a $20^{\circ} \mathrm{C}$ e pode ser identificado analiticamente. ${ }^{17}$

\section{CONCLUSÃO}

A reação de ozonólise ${ }^{18}$ é uma das reações mais limpas, reprodutíveis e inúmeros exemplos podem ser encontrados na literatura, ${ }^{19}$ tanto como aplicações de laboratório como em aplicações industriais. O entendimento racional do mecanismo da reação de ozonólise tem permitido avanços recentes em uma reação com cerca de 200 anos de idade. ${ }^{20,21}$ Atualmente seu mecanismo está bem comprovado, no entanto o desenvolvimento das ideias e experimentos que permitiram estas conclusões muitas vezes são omitidos. Por outro lado, um dos elementos mais interessantes na história do estabelecimento do mecanismo desta reação foi o desenvolvimento dos vários instrumentos para geração e dos equipamentos de análise necessários à comprovação das hipóteses apresentadas, muitas delas entre o final do século XIX e início do século XX. ${ }^{1}$

\section{MATERIAL SUPLEMENTAR}

Está disponível em http://quimicanova.sbq.org.br, em arquivo PDF, com acesso livre e apresenta os geradores de ozônio.

\section{REFERÊNCIAS}

1. Kogelschatz, U.; Eliasson, B.; Egli, W.; Pure Appl. Chem. 1999, 71, 1819; Schönbein, C. F.; Poggendorffs Ann. Phys. Chem. 1840, 50, 616.

2. Rubin, M. B.; Bull. Hist. Chem. 2001, 26, 40.

3. Riedeal, E. K. Em A Treatese of Electro-Chemistry; Blount, B., ed.; Constable \& Company LTD.: London, 1920.

4. Friend, J. N.; Twiss, D. F. Em A Text-Book of Inorganic Chemistry, Vol. VII, Part I - Oxygen; Friend, J. N., ed.; Charles Griffin \& Company, Limited: London, 1924, cap. 5.

5. Bailey, P. S.; Ozonation in Organic Chemistry, Academic Press: New York, vol. 1, 1978; Kula, J.; Chem. Health Saf. 1999, 6, 21; Gordon, P. M.; Chem. Eng. News 1990, 68, 2.
6. Long Jr., L.; Chem. Rev. 1940, 27, 437. Na época acreditava-se que a molécula de dióxido de enxofre $\left(\mathrm{SO}_{2}\right)$ era planar. Na verdade, existe um ângulo de ligação de $119^{\circ}$.

7. Rubin, M. B.; Helv. Chim. Acta 2003, 86, 930. Artigo dedicado exclusivamente ao trabalho de C. D. Harries, casado com Herta von Siemens, filha de Werner von Siemens, patriarca da indústria eletroeletrônica (hoje Siemens AG) que desenvolveu um dos primeiros geradores de ozônio baseado no efeito corona.

8. Lowry, T.W.; Trans. Faraday Soc. 1923, 18, 285; Staudinger, H.; Chem. Ber. 1925, 58, 1088; Bailey, P. S.; Carter, T. P.; Fischer, C. M.; Thompson, J. A.; Can. J. Chem. 1973, 51, 1278.

9. Hughes, R. H.; J. Chem. Phys. 1956, 24, 131

10. Tanaka, T.; Morino, Y.; J. Mol. Spectrosc. 1970, 33, 538.

11. Criegee, R.; Becher, P.; Chem. Ber. 1957, 90, 2516; Criegee, R.; Blust, G.; Zinke, H.; Chem. Ber. 1954, 87, 766; Criegee, R.; Kerckrow, A.; Zinke, H.; Chem. Ber. 1955, 88, 1878.

12. Solventes inertes são aqueles que não reagem com o zwitterion, por exemplo, pentano, hexano, heptano, ciclo-hexano, diclorometano, benzeno, cloreto de etila e anidrido acético. Solventes ativos: metanol, etanol, isopropanol, água, ácido acético, acetona-água.

13. Huisgein, R.; Angew. Chem., Int. Ed. 1963, 2, 565.

14. Criegee, R.; Angew. Chem., Int. Ed. 1975, 14, 745.

15. Durham, L. J.; Greenwood, F. L.; Chem.Commun. 1967, 843.

16. Nazarov, A. M.; Yamilova, G. A.; Komissarov, V. D.; React. Kinet. Catal. Lett. 2000, 71, 363.

17. Block, K.; Kappert, W.; Kirschfeld, A.; Muthusamy, S.; Schroeder, K.; Sander, W.; Kraka, E.; Sosa, C.; Cremer, D. Em Peroxide Chemistry: Mechanistic and Preparative Aspects of Oxygen Transfer; Adam, W., ed.; Wiley, 2001, http://onlinelibrary.willey.com/ doi/10.1002/3527600396.ch7/summary, acessada em Janeiro 2012.

18. No material suplementar são apresentados os detalhes necessários para a construção de um gerador de ozônio baseado no efeito corona que pode ser construído por um custo abaixo de $\mathrm{R} \$ 150,00$. A revista Organic Synthesis (www.orgsyn.org) apresenta um procedimento experimental detalhado: Organic Synthesis 1955, Coll. Vol. 3, p. 673; 1946, Vol. 26, p. 63.

19. Uma busca usando a base de dados Scifinder, em 2011, revela dezenas de milhares de artigos com aplicações e desenvolvimentos da reação de ozonólise.

20. Schwartz, C.; Raible, J.; Mott, K.; Dussault, P. H.; Tetrahedron 2006, 62, 10747 .

21. Schiaffo, C. E.; Dussault, P. H.; J. Org. Chem. 2008, 73, 4688. 
Alfredo R. M. Oliveira* e Celso L.Wosch

Departamento de Química, Universidade Federal do Paraná, CP 19081, 81531-990 Curitiba - PR, Brasil

\section{GERADORES DE OZÔNIO}

O gás ozônio pode ser gerado de três maneiras diferentes: eletrólise de soluções ácidas diluídas; fotoquímica e descarga elétrica silenciosa, sendo esta última, desenvolvida por Siemens, ${ }^{6}$ a mais utilizada.

O principio de funcionamento é relativamente simples: a aplicação de uma alta voltagem (10-30 KV) entre dois eletrodos isolados por um dielétrico produz um campo elétrico, que é capaz de gerar ozônio a partir do gás oxigênio presente entre os elementos dielétricos. Este tipo de gerador normalmente é composto por três etapas: fonte de alta voltagem, tubo de descarga silenciosa e descarte. A fonte de alta voltagem mais comum é o autotransformador ou transformador para lâmpadas neon, no entanto, estes transformadores são pesados e caros, tornando a manutenção do equipamento difícil. Com os recentes avanços na eletrônica estes transformadores antigos foram substituídos por circuitos mais baratos e simples. No Esquema $1 \mathrm{~S}$ está representado um circuito eletrônico que pode gerar até $24.000 \mathrm{v}$ de tensão com uma frequência de trabalho de até $27 \mathrm{kHz}$. Este circuito é composto por uma etapa osciladora e uma bobina automotiva, que faz o papel de transformador. Com este circuito, a partir de uma tensão de $12 \mathrm{v}$ em corrente contínua é possível gerar até $24.000 \mathrm{v}$ pulsados.

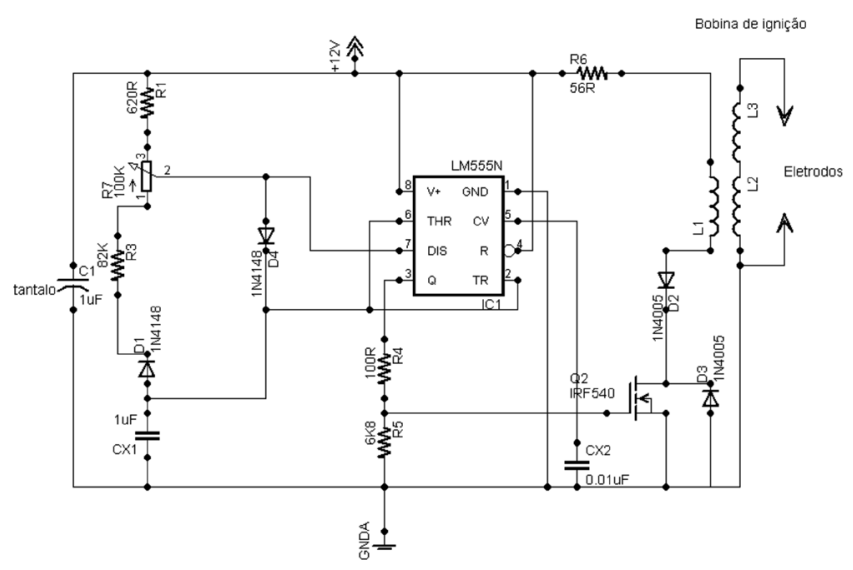

Esquema 1S. Circuito de alta voltagem para o gerador de ozônio

ATENÇÃO: Recomenda-se muito cuidado ao manusear este tipo de circuito. O risco de choque elétrico é grande, como em qualquer aparelho deste tipo. Recomenda-se que o aparelho TODO seja acondicionado em uma caixa metálica devidamente aterrada.

O tubo de descarga silenciosa pode ser feito conforme o Esquema $2 \mathrm{~S}$.

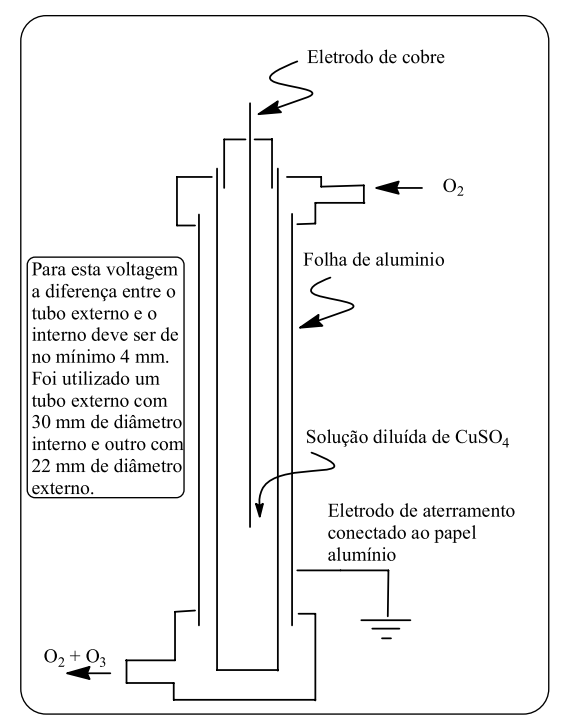

Esquema 2S. Diagrama de um tubo de descarga silenciosa (corona)

O descarte deve ser feito com um borbulhador contendo uma solução de 5\% KI com amido. Assim que a reação de ozonólise se completa, o excesso de ozônio reage com o KI/amido formando uma cor escura característica do complexo $\mathrm{I}_{2} /$ amido; neste momento, o aparelho deve ser desligado e o excesso de ozônio em solução deve ser retirado com o auxílio de um fluxo de oxigênio ou nitrogênio.

\section{Análise da quantidade de ozônio formado}

A análise é feita pela passagem de um volume conhecido de oxigênio através do tubo gerador de ozônio e borbulhado em dois frascos contendo $70 \mathrm{~mL}$ de uma solução neutra de iodeto de potássio a $2 \%$ cada um. A solução total resultante é acidificada com ácido sulfúrico $10 \%$ (cerca de $15 \mathrm{~mL}$ ) e titulada com uma solução padronizada de tiossulfato de sódio $0,1 \mathrm{~mol} / \mathrm{L}$ usando amido solúvel como indicador. 